\title{
Alkane Hydroxylation by a Nonheme Iron Catalyst that Challenges the Heme Paradigm for Oxygenase Action
}

\author{
Anna Company,,${ }^{\mathrm{a}, \mathrm{b}}$ Laura Gómez, ${ }^{\mathrm{a}}$ Mireia Güell, ${ }^{\mathrm{a}}$ Xavi Ribas, ${ }^{\mathrm{a}}$ Josep M. Luis, ${ }^{\mathrm{a}}$ Lawrence Que Jr, ${ }^{\mathrm{b}, *}$ and \\ Miquel Costas ${ }^{a, *}$ \\ ${ }^{a}$ Departament de Química and Institut de Química Computacional, Campus de Montilivi, Universitat de Girona, E- \\ 17071 Girona, Spain. ${ }^{b}$ Department of Chemistry and Center for Metals in Biocatalysis, University of Minnesota, \\ Minneapolis, Minnesota 55455
}

RECEIVED DATE (will be automatically inserted after manuscript is accepted)

Selective oxidation of hydrocarbons under mild conditions constitutes a major challenge of modern chemistry. ${ }^{1}$ Nonheme iron enzymes like methane monooxygenase ${ }^{2}$ and Rieske dioxygenases $^{3}$ catalyze such reactions and have inspired the development of synthetic models as alkane oxidation catalysts. ${ }^{4}$ Exceptional nonheme iron catalysts are those containing tetradentate $\mathrm{N}_{4}$ ligands belonging to the tripodal TPA and linear BPMEN family that can perform efficient stereospecific alkane hydroxylation using $\mathrm{H}_{2} \mathrm{O}_{2}$ as oxidant. ${ }^{4}$ These bioinspired catalysts have provided key insights into the mechanisms by which alkanes are oxidized by enzymes. The common mechanism invoked in these studies follows the heme paradigm ${ }^{5}$ in which a high valent iron-oxo species first abstracts an $\mathrm{H}$-atom from a substrate $\mathrm{C}-\mathrm{H}$ bond and the incipient alkyl radical then rebounds with the nascent $\mathrm{Fe}-\mathrm{OH}$ moiety to form the product $\mathrm{C}-\mathrm{O}$ bond (Scheme 1). ${ }^{2,4}$ Labeling studies indicate that the $\mathrm{O}$ atom introduced into the substrate $\mathrm{C}-\mathrm{H}$ bond derives mainly from the $\mathrm{H}_{2} \mathrm{O}_{2}$ oxidant. However a minor fraction incorporates an $\mathrm{O}$ atom from water into the product, which is explained by oxo-hydroxo tautomerism of the high-valent $\mathrm{Fe}=\mathrm{O}$ oxidant. ${ }^{5,6}$ Herein we describe a new remarkably efficient nonheme iron catalyst in the stereospecific oxidation of alkanes using $\mathrm{H}_{2} \mathrm{O}_{2}$ as oxidant that yields alcohol products with an unexpectedly large fraction of their oxygen atoms derived from water. This unprecedented result challenges the established heme paradigm and sheds new light into how nonheme iron centers may differ from heme centers in their mode of oxidative action.

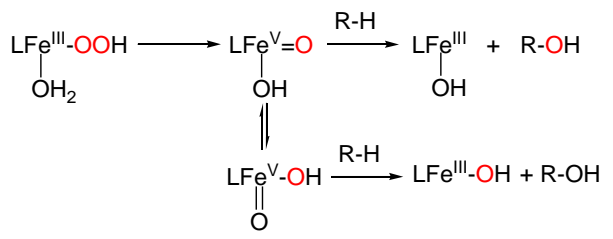

Scheme 1

Iron complex [Fe $\left.{ }^{\mathrm{II}}\left(\mathrm{CF}_{3} \mathrm{SO}_{3}\right)_{2}\left({ }^{\mathrm{Me}} 2 \mathrm{PyTACN}\right)\right]$ (1) (see Figure 1) was prepared and structurally characterized (for details, see Sup. info). Its crystal structure presents a distorted octahedral iron(II) center having a tetradentate ${ }^{\mathrm{Me} 2 \mathrm{PyTACN}}$ ligand and two triflate anions coordinated cis to each other.

Complex $\mathbf{1}$ is a very efficient catalyst for the hydroxylation of cyclohexane by $\mathrm{H}_{2} \mathrm{O}_{2}$. When 10 equiv $\mathrm{H}_{2} \mathrm{O}_{2}$ were delivered by syringe pump together with 1000 equiv water, 6.0 turnover numbers (TN) of cyclohexanol (A) and $0.5 \mathrm{TN}$ of cyclohexanone $(\mathrm{K})(\mathrm{A} / \mathrm{K}=12)$ were obtained, corresponding to a $65 \%$ efficiency in the conversion of $\mathrm{H}_{2} \mathrm{O}_{2}$ into products. Both efficiency and $\mathrm{A} / \mathrm{K}$ selectivity exhibited by $\mathbf{1}$ were comparable to values reported for $\left[\mathrm{Fe}^{\mathrm{II}}(\mathrm{BPMEN})\left(\mathrm{CH}_{3} \mathrm{CN}\right)_{2}\right]^{2+}(63 \%$ yield and $\mathrm{A} / \mathrm{K}=8)$, considered the prototypical example of an efficient stereospecific alkane hydroxylation catalyst. ${ }^{4 \mathrm{~b}}$ Additional evidence implicated a metalbased oxidant rather than $\mathrm{HO} \cdot$. The intermolecular kinetic isotope effect evaluated in the hydroxylation of a 1:3 molar mixture of cyclohexane and its deutero-analogue was 4.3. In addition 1 oxidized adamantane with a large $3 \% 2^{\circ}$ normalized selectivity (30). Lastly, the oxidation of cis-1,2-dimethylcyclohexane (cis$\mathrm{DMCH}$ ) afforded the tertiary alcohol product with $93 \%$ retention of configuration. Overall, these characteristics are consistent with those of some previously described nonheme iron complexes. ${ }^{4}$
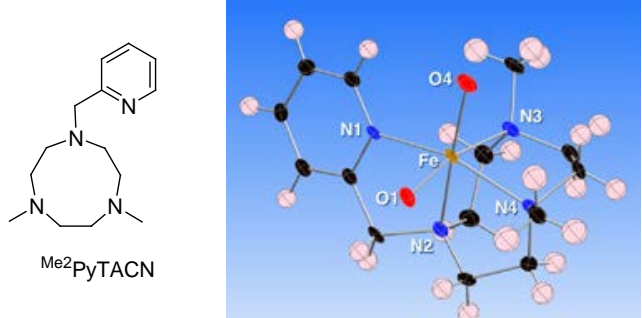

Figure 1. Left, schematic representation of the ligand. Right, thermal ellipsoid plot (50\% probability) of $\mathbf{1}$; triflate ligands (except for the $\mathrm{O}$ atoms bound to $\mathrm{Fe}$ ) omitted for clarity.

Interestingly, ${ }^{18} \mathrm{O}$-labeling experiments in the hydroxylation of different alkanes catalyzed by $\mathbf{1}$ revealed intriguing differences between this catalyst and previously reported non-heme $\mathrm{N}_{4} \mathrm{Fe}$ systems. The oxidation of cyclohexane by 1 with 10 equiv $\mathrm{H}_{2}{ }^{18} \mathrm{O}_{2}$ in the presence of 1000 equiv $\mathrm{H}_{2}{ }^{16} \mathrm{O}$ afforded $47 \%{ }^{18} \mathrm{O}$-labeled cyclohexanol. Complementary experiments with 10 equiv $\mathrm{H}_{2} \mathrm{O}_{2}$ and 1000 equiv $\mathrm{H}_{2}{ }^{18} \mathrm{O}$ yielded $42(3) \%{ }^{18} \mathrm{O}$-labeled cyclohexanol. The same levels of label incorporation from $\mathrm{H}_{2}{ }^{18} \mathrm{O}$ were observed in the hydroxylation of cyclooctane (Table 1). This level of oxygen incorporation from water was the highest for any synthetic nonheme catalyst thus far. Furthermore, when oxidations of cyclohexane were carried out with different $\mathrm{H}_{2}{ }^{18} \mathrm{O}$ concentrations, the fraction of ${ }^{18} \mathrm{O}$-labeled cyclohexanol (\% $\mathrm{R}^{18} \mathrm{OH}$ ) increased linearly with the amount of $\mathrm{H}_{2}{ }^{18} \mathrm{O}$ at lower $\mathrm{H}_{2}{ }^{18} \mathrm{O}$ concentrations, but plateaued at $42(3) \%$ at higher concentrations (Figure S2), suggesting the involvement of a water binding pre-equilibrium, as precedented for Fe(TPA). ${ }^{4 \mathrm{~b}}$ These results support the mechanism shown in Scheme 1 proposed for $\mathrm{Fe}(\mathrm{TPA})$ and $\mathrm{Fe}(\mathrm{BPMEN})$ catalysis in which a $\mathrm{HO}-\mathrm{Fe}^{\mathrm{V}}=\mathrm{O}$ oxidant is formed via water-assisted heterolysis of the $\mathrm{O}-\mathrm{O}$ bond of a $\mathrm{H}_{2} \mathrm{O}-\mathrm{Fe}^{\mathrm{III}}-\mathrm{OOH}$ intermediate. ${ }^{4 b, 7}$ If complete oxo-hydroxo tautomerism ${ }^{5,6}$ of the $\mathrm{HO}-\mathrm{Fe}^{\mathrm{V}}=\mathrm{O}$ moiety occurred, a maximum value of $50 \%$ would be expected for the amount of labeled water incorporated into the alcohol product. The $\mathrm{H}_{2}{ }^{18} \mathrm{O}$ labeling results described above clearly approach this maximum, so that the $\mathrm{C}-\mathrm{O}$ bond that is formed can be made with either the oxygen from $\mathrm{H}_{2} \mathrm{O}_{2}$ or the oxygen from $\mathrm{H}_{2} \mathrm{O}$ with almost equal probability. 
Table 1. $\%^{18} \mathrm{O}$ incorporation into alcohol products by various $\mathrm{Fe}(\mathrm{L})$ catalysts in the presence of 1000 equiv $\mathrm{H}_{2}{ }^{18} \mathrm{O}$

\begin{tabular}{lcc}
\hline Substrate & Me2$^{2}$ PyTACN & TPA $^{4 \mathrm{~b}}$ \\
\hline Cyclohexane & 42 & 29 \\
Cyclohexane- $d_{12}$ & 40 & 35 \\
Cyclooctane & 44 & 23 \\
cis-DMCH $\left(3^{\circ} \mathrm{C}-\mathrm{H}\right)$ & 79 & 6 \\
Adamantane $\left(3^{\circ} \mathrm{C}-\mathrm{H}\right)$ & 74 & 6 \\
2,3-Dimethylbutane & 76 & - \\
\hline
\end{tabular}

Surprisingly, even higher levels of $\mathrm{H}_{2}{ }^{18} \mathrm{O}$ incorporation $(76 \pm 3$ $\%)$ were obtained for alcohol products in the oxidation of alkanes with tertiary C-H bonds, such as adamantane, cis-DMCH, and 2,3-dimethylbutane. Furthermore this unexpectedly large value was found to be independent of substrate concentration (25-1000 $\mathrm{mM}$ ). This observation strongly implicates the $\mathrm{HO}-\mathrm{Fe}^{\mathrm{V}}=\mathrm{O}$ species as the only oxidant capable of alkane oxidation in the case of $\mathbf{1}$.

The labeling results for $\mathbf{1}$ differ significantly from those reported for $\mathrm{Fe}(\mathrm{TPA})$ (Table 1). For the latter catalyst, label incorporation from $\mathrm{H}_{2}{ }^{18} \mathrm{O}$ into substrates with $2^{\circ} \mathrm{C}-\mathrm{H}$ bonds decreased with the $\mathrm{C}-\mathrm{H}$ bond strength and labeling of $2^{\circ}$-ol products was much higher than for $3^{\circ}$-ol products. These results suggested that $\mathrm{C}-\mathrm{H}$ bond cleavage and oxo-hydroxo tautomerism were competitive processes, as also found for iron porphyrin complexes. ${ }^{4 b, 5,6}$ However this was not the case for $\mathbf{1}$, since higher water incorporation was observed in the oxidation of the weaker $3^{\circ} \mathrm{C}-\mathrm{H}$ bonds and this level of incorporation was independent of cis-DMCH concentration. To rationalize the high level of label incorporation, we considered the possibility that a carbocation intermediate was formed and subsequently trapped by water, but discarded it because of the high retention of configuration observed for cis-DMCH hydroxylation. We also considered the possibility that the $\mathrm{HO}-\mathrm{Fe}^{\mathrm{V}}=\mathrm{O}$ oxidant became doubly labeled by rapid, multiple intermolecular exchanges with $\mathrm{H}_{2}{ }^{18} \mathrm{O}$, but rejected it on the basis of a $\mathrm{H}_{2}{ }^{18} \mathrm{O}$ labeling experiment where cyclohexane and cis-DMCH were oxidized in competition with each other. cisDMCH reacted much faster than cyclohexane, and so should have a shorter lived oxidant. Nevertheless the $3^{\circ}$-ol thus formed contained $74 \%$ label from water while cyclohexanol contained only $38 \%$. Thus the difference in label incorporation cannot be determined by how much ${ }^{18} \mathrm{O}$ is present in the common $\mathrm{Fe}^{\mathrm{V}}$ oxidant, and a modified mechanistic scenario is required for $\mathbf{1}$.

In Scheme 2, we propose a scenario in which the structure of the substrate can play a role in determining the course of C-O bond formation. For 1, the two $\mathrm{Fe}^{\mathrm{V}}(\mathrm{O})(\mathrm{OH})$ isomers ( $\mathbf{A}$ and $\mathbf{B}$ ) in equilibrium via oxo-hydroxo tautomerism are distinct, since the ligands trans to the oxo and hydroxo groups are not chemically equivalent and the orientations of the pyridine ligand relative to the $\mathrm{Fe}=\mathrm{O}$ bond are different. No matter which isomer abstracts the $\mathrm{H}$-atom from substrate, a common $\mathrm{Fe}^{\mathrm{IV}}(\mathrm{OH})_{2}$ species is formed. The cis configuration of the two hydroxo groups differs from the trans configuration required in heme complexes and is a unique feature of these nonheme iron catalysts. Thus the alkyl radical can in principle rebound with either $\mathrm{OH}$ group, the outcome of which determines the $\% \mathrm{H}_{2}{ }^{18} \mathrm{O}$ incorporation. Given that these values range from $40 \%$ for cyclohexane- $d_{12}$ to $79 \%$ for cis-DMCH, the energy difference between the two possible rebound trajectories is $<2 \mathrm{kcal} \mathrm{mol}^{-1}$, which is consistent with DFT calculations. ${ }^{8}$ Thus the labeling results indicate that $2^{\circ}$-alkyl radicals do not discriminate between the two $\mathrm{OH}$ groups, but $3^{\circ}$ alkyl radicals favor rebound with the $\mathrm{OH}$ group derived from water. Perusal of the structure of 1 (Figure 1) suggests steric effects may provide a possible rationale for this preference, since the hemisphere surrounding $\mathrm{O} 1$ is less sterically congested.

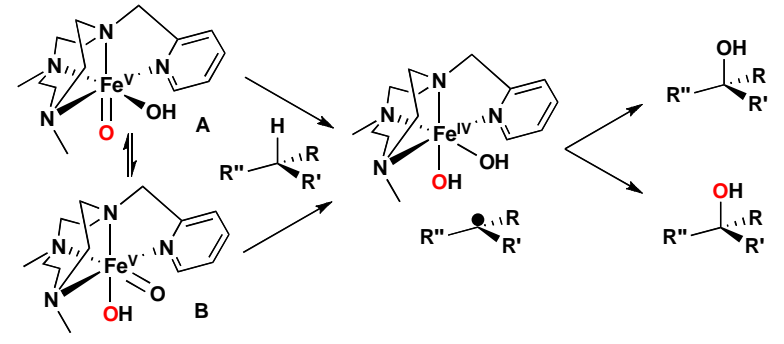

Scheme 2

In conclusion, $\mathbf{1}$ is an efficient alkane hydroxylation catalyst that can incorporate surprisingly large amounts of water into products via an unusual rebound-like mechanism. A similar mechanism may be operating in the hydroxylation of indane to 1indanol by toluene or naphthalene dioxygenase to account for the high level of $\mathrm{H}_{2}{ }^{18} \mathrm{O}$ incorporation (68\%) found. ${ }^{9}$ In addition, the $\alpha$-ketoglutarate-dependent halogenases represent an established biological example in which $\mathrm{C}-\mathrm{H}$ bond cleavage initiated by an $\mathrm{Fe}=\mathrm{O}$ moiety is consummated by rebound not with the incipient $\mathrm{OH}$ group but with the adjacent halide ligand. ${ }^{10}$ Thus $\mathbf{1}$ may serve as a model for this unusual enzymatic chemistry, which suggests that a broader mechanistic landscape than in heme systems applies to non-heme sites.

Acknowledgment. Financial support from MCYT of Spain (CTQ2006-05367 to MC) and from US-DOE (DE-FG02-03ER15455 to LQ) is gratefully acknowledged. AC, LG and MG thank MEC for PhD grants.

Supporting Information Available: Experimental procedures for the preparation of $\mathbf{1}$ and for the oxidation reactions and the cif file for $\mathbf{1}$. This material is available free of charge via the Internet at http://pubs.acs.org.

\section{References}

1) a) Tanase, S.; Bouwman, E. Adv. Inorg. Chem. 2006, 58, 29-75. b) Biomimetic Oxidations Catalyzed by Transition Metal Complexes; Imperial College Press: London, 2000.

2) Merkx, M.; Kopp, D. A.; Sazinsky, M. H.; Blazyk, J. L.; Müller, J.; Lippard, S. J. Angew. Chem. Int. Ed. 2001, 40, 2782-2807.

3) a) Costas, M.; Mehn, M. P.; Jensen, M. P.; Que, L., Jr. Chem. Rev. 2004, 104, 939. b) Abu-Omar, M. M.; Loaiza, A.; Hontzeas, N. Chem. Rev. 2005, 105, 2227.

4) a) Costas, M.; Chen, K.; Que, L., Jr. Coord. Chem. Rev. 2000, 200-202, 517. b) Chen, K.; Que, L., Jr. J. Am. Chem. Soc. 2001, 123, 6327. c) Britovsek, G. J. P.; England, J.; White, A. J. P. Inorg. Chem. 2005, 44, 8125. d) Mekmouche, Y.; Ménage, S.; Toia-Duboc, C.; Fontecave, M.; Galey, J.-B.; Lebrun, C.; Pécaut, J. Angew. Chem. Int. Ed. 2001, 40, 949 5) a) Meunier, B.; de Visser, S. P.; Shaik, S. Chem. Rev. 2004, 104, 39473980. b) Groves, J. T.; Han, Y. Z. In Cytochrome P450: Structure, Mechanism and Biochemistry; Ortiz de Montellano, P. R., Ed.;Plenum: NY, 1995. c) Bernadou, J.; Meunier, B. Chem. Commun. 1998, 2167. 6) a) Bernadou, J.; Fabiano, A.-S.; Robert, A.; Meunier, B. J. Am. Chem. Soc. 1994, 116, 9375. b) Groves, J. T.; Lee, J.; Marla, S. S. J. Am. Chem. Soc. 1997, 119, 6269. c) Lee, K. A.; Nam, W. J. Am. Chem. Soc. 1997, 119, 1916.

7) a) Bassan, A.; Blomberg, M. R. A.; Siegbahn, P. E. M.; Que, L., Jr., J. Am. Chem. Soc. 2002, 124, 11056. b) Quinonero, D.; Morokuma, K.; Musaev, D. G.; Mas-Balleste, R.; Que, L., Jr. J. Am. Chem. Soc. 2005, $127,6548$.

8) DFT calculations were done using cyclohexane as a substrate. Geometries were optimized at the B3LYP level in junction of the LANL2DZ basis set with associated ECP for Fe. The energies were further refined by single point calculations using the SDD basis set with associated ECP for Fe and 6-311G(d,p) basis sets on the other atoms as implemented in the Gaussian 03 program.

9) Wackett, L. P.; Kwart, L. D.; Gibson, D. T. Biochemistry 1988, 27, 1360-1367.

10) Galonic, D. P.; Barr, E. W.; Walsh, C. T.; Bollinger, J. M., Jr.; Krebs, C. Nat. Chem. Biol. 2007, 3, 113. 


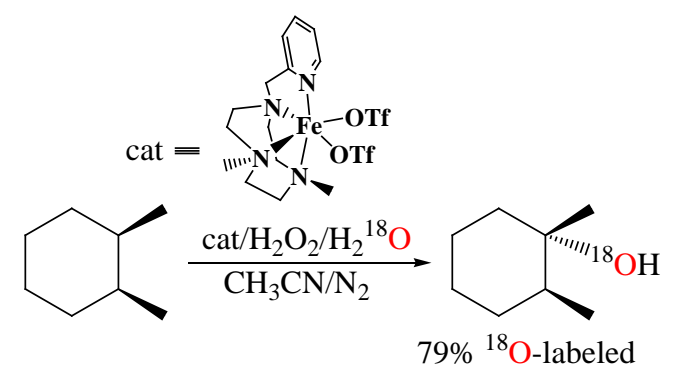

\section{Abstract}

A nonheme iron catalyst catalyzed stereoselective oxidation of alkanes with $\mathrm{H}_{2} \mathrm{O}_{2}$ with remarkable efficiency and exhibiting an unprecedented high incorporation of water into the oxidized products. The present results challenge the canonical description of oxygenases, the standard oxo-hydroxo tautomerism that applies to heme systems and serves as a precedent for alternative pathways for the oxidation of hydrocarbons at nonheme iron oxygenases. 